\title{
CONGENITAL HORNER SYNDROME: A RARE THOUGH SIGNIFICANT COMPLICATION OF SUBCLAVIAN FLAP AORTOPLASTY
}

\author{
Sody Abby Naimer, MD, ${ }^{\mathrm{a}}$ Orly Weinstein, $\mathrm{MD},{ }^{\mathrm{b}}$ and Gidon Rosenthal, $\mathrm{MD},{ }^{\mathrm{b}}$ Beersheva, Israel
}

Horner syndrome is a condition that can arise at any age as a result of disease of the ophthalmic branch of the cervicothoracic sympathetic nerves. Its causes range from malignant tumors to traumatic insults. ${ }^{1,2}$ The classic tetrad includes ptosis, anhydrosis, enophthalmus, and miosis. Congenital Horner syndrome, despite its name, results from both congenital and early-acquired damage to structures of the ophthalmic sympathetic pathway. This variant is rare and comprises no more than $5 \%$ of cases of Horner syndrome. The additional feature of heterochromia characterizes it as a diversity of color between the left and right eyes, owing to hypochromia of the affected iris. ${ }^{3}$ This is a direct result of the denervation of the target organ at its early stage of development. Although ptosis is seldom missed, at a very young age, when eyes are kept closed most of the day, eyelid abnormalities may go unnoticed and, without scrutiny, the full syndrome may not be apparent.

The natural tendency of a clinician is to automatically assume that anatomic defects appearing in the newborn are congenital defects. This holds true so often that other acquired causes, such as major surgery in this case, may be overlooked.

Clinical summary. The female patient was born after a normal pregnancy and term delivery and was released from the nursery with a reported normal examination. Five days later she was admitted to the pediatric intensive care unit with cyanosis, hypothermia, and diminished intake of food. On examination, a harsh cardiac murmur was heard and femoral pulses were absent. Echocardiography revealed a patent ductus arteriosus, atrial and ventricular septal defects, and coarc-

From the Goosh Katif Family Health Center, ${ }^{a}$ Gaza Shore, Israel; Emergency Medicine Department, Soroka Medical Center, Beersheva; the Department of Family Medicine, Faculty of Health Sciences, Ben Gurion University, Beersheva, Israel; and the Ophthalmology Department, Soroka Medical Center, ${ }^{\mathrm{b}}$ Beersheva, Faculty of Health Sciences, Ben Gurion University, Beersheva, Israel.

Received for publication Jan 11, 2000; accepted for publication Feb $25,2000$.

Address for reprints: Sody Abby Naimer, MD, Goosh Katif Health Center, Neve Dekalim POB Hof Gaza, Israel 79779 (E-mail: sody@netvision.net.il).

J Thorac Cardiovasc Surg 2000;120;419-21

Copyright $\odot 2000$ by The American Association for Thoracic Surgery

$0022-5223 / 2000 \$ 12.00+0 \quad \mathbf{1 2 / 5 4 / 1 0 7 3 4 0}$

doi: $10.1067 / \mathrm{mtc} .2000 .107340$

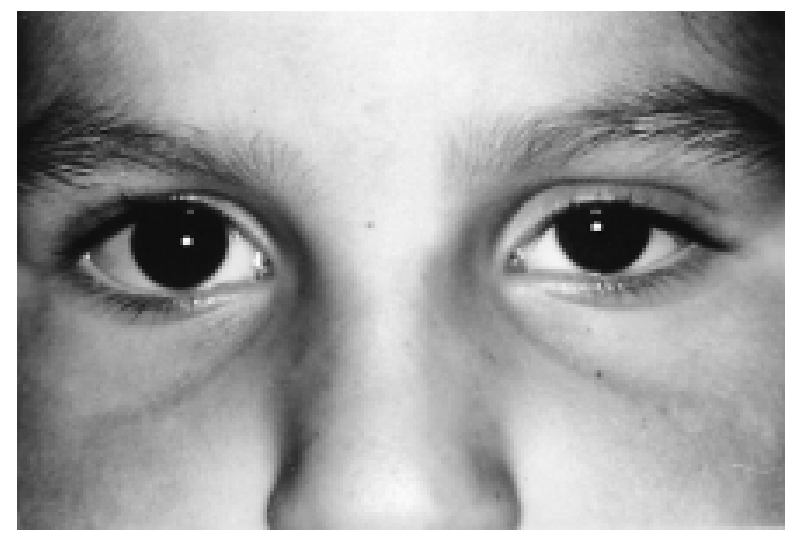

Fig 1. Patient's appearance at the age of 3 years. Prominent ptosis and enophthalmus are evident. Miosis and heterochromia are the more subtle features.

tation of the aorta. Three days later the thoracic surgeons performed a subclavian flap aortoplasty. On her release, in the course of the second week of life, after recovery from a left pneumothorax, prominent left eye ptosis was noticed and was assumed to be congenital. This finding was ignored since there was no obstruction of vision of the eye. At 6 weeks of age investigation of poor weight gain disclosed massive gastroesophageal reflux as well.

Doppler echocardiography performed at a follow-up visit years later demonstrated a growing pressure gradient across the aortic root. At the age of 3 years, percutaneous aortoplasty was performed and succeeded in decreasing the pressure gradient. The discharge letter recorded the existence of unexplained anisocoria and facial asymmetry. It was only then, for the first time, that the child's family physician realized the presence of heterochromia. The patient's father admitted that it seemed odd to him that the left eye was of a much brighter color than the right, although the parents had not noticed any difference in skin color or perspiration patterns between the two sides of the face. At this point, at the age of 3 years, the complete picture of congenital Horner syndrome was diagnosed. The child was referred for an ophthalmologic examination, which disclosed normal visual acuity and external ocular movements. Ptosis of the left upper eyelid down to the pupillary level was noticed (Fig 1), together with anisocoria and heterochromia (hypopigmented left iris). The pupils were round and reactive to light but unequal, with the left pupil smaller than the right. Her parents had then noticed sweating of only the right side of her face. 


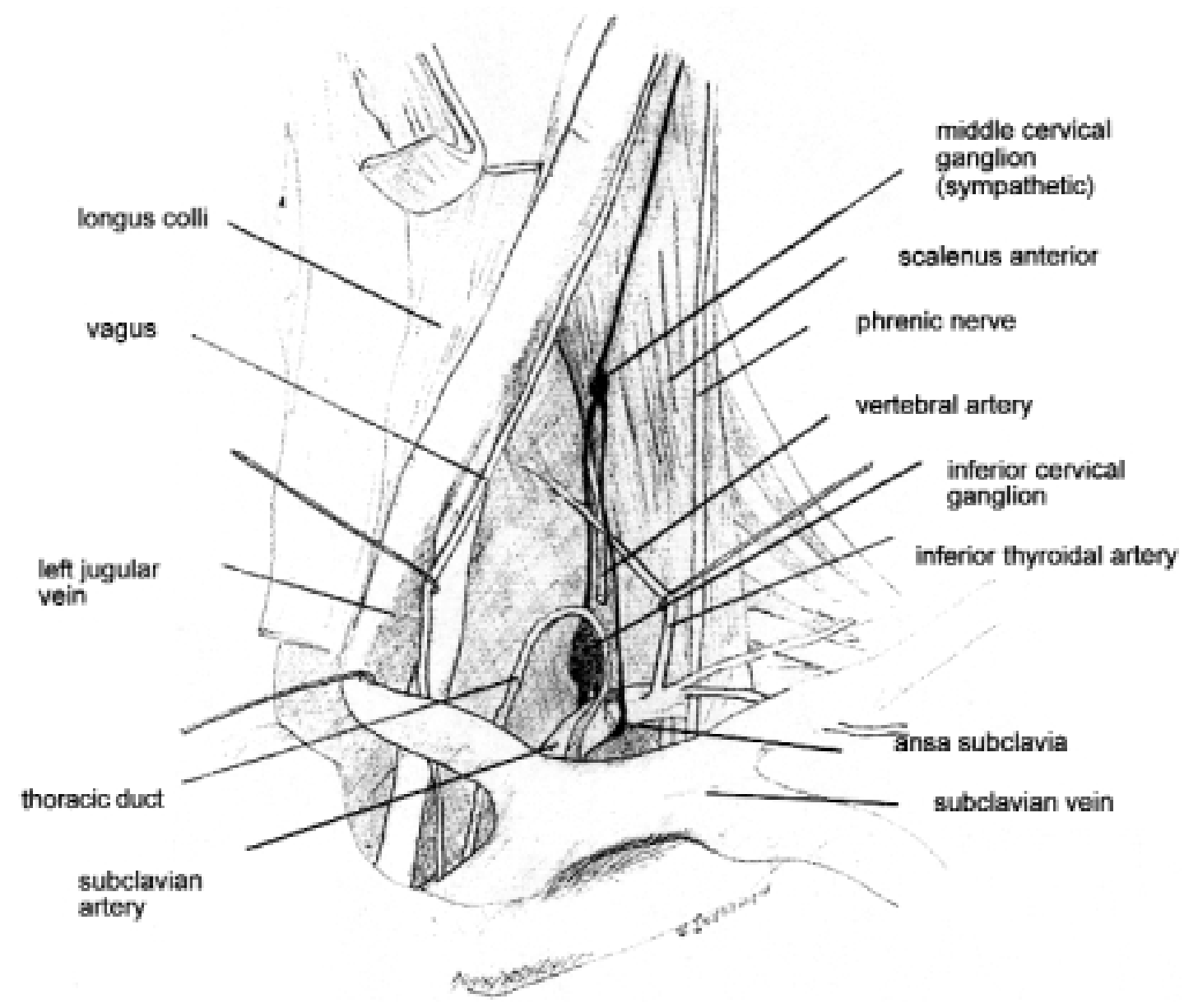

Fig 2. Anatomy of sympathetic pathway showing first-order central neuron, second-order intermediate neuron, and third-order neuron pathways. Note the proximity of proximal second-order neuron to the subclavian artery.

After the instillation of $4 \%$ cocaine eye drops to both eyes, a dilatation of the right pupil was noted while the left pupil remained unchanged. A diagnosis of left-sided congenital Horner syndrome was confirmed.

Discussion. Subclavian flap aortoplasty has evolved into a popular and recommended treatment for coarctation of the aorta. This procedure performed in infancy is relatively safe, with few but sometimes devastating complications, including paraplegia, chylothorax/pneumothorax, hemorrhage, laryngeal nerve paralysis, and phrenic nerve damage. A MEDLINE search of the medical literature since 1966 revealed no direct report associating thoracic surgery with ocular sympathetic nerve damage. In a single report, a child was born with Turner syndrome, coarctation of the aorta, and an aortic aneurysm. Horner syndrome was diagnosed at the age of 7 years and was attributed to traction on the ascending preganglionic sympathetic fibers. ${ }^{4}$ However, a survey of 18 different series of patients undergoing subclavian flap aortoplasty discovered 2 studies that mentioned such a possibility. The first by Baudet and al-Qudah ${ }^{5}$ in 1989 summarized the results of flap repair of coarctation in 22 infants. They saw a single case of transient Horner syndrome. The authors found it difficult to specifically remember the operation, which was held many years earlier, and did not recall any specific anatomic abnormality or technical difficulty at the time. This complication suggests partial damage to the nerve during the operation, which later resolved spontaneously. Van Heurn and associates 5 presented their results of 152 such interventions in 1994. They found that 2 infants whose aortoplasties extended into the subclavian artery were left with persistent Horner syndrome. The fact that these authors saw 2 such complications whereas the many others did not report a single case raises the suspicion that the other surgeons did not seek this phenomenon. It seems reasonable to assume that the thoracic surgeons, concentrating on the various aspects of the cardiovascular problems of their patients, may have overlooked complications arising in a different body system. This is particularly feasible in the neonate, in whom the surgical anatomy is cramped, making this complication 
more likely to occur and facial asymmetry easier to miss. The true incidence of this complication can be determined only by re-examining all those undergoing subclavian flap aortoplasty. In our case, as above, the leading cardiovascular surgeon reported an absolutely normal course of the operation. The instillation of cocaine drops supports the diagnosis of proximal nerve fault and not an end organ defect.

The anatomic course of the ophthalmic branch of the cervical sympathetic nerves is what provides the basis for potential danger of harming these nerves while performing thoracic surgery (Fig 2). The unprecedented entrance of the nerve into the thorax, winding around the subclavian artery, then ascent to enter the skull renders it susceptible to accidental injury when the area of the main vessels is manipulated.

Subclavian flap aortoplasty may be a significant cause for this syndrome in the small group of infants exhibiting it.

In conclusion, we have reported a case of congenital Horner syndrome that resulted from an attempt to correct a congenital aortic defect. This case may represent a larger number of unidentified cases passing under the surgeon's hands. We believe that the question to be raised should be whether to adopt a policy of dissecting the sympathetic nerve while performing subclavian flap aortoplasty to prevent irreversible injury.

\section{REFERENCES}

1. Balcer LJ, Galleta SL. Pancoast's syndrome. N Engl J Med 1997;337:1359.

2. Firlik AD, Welch WC. Brown-Sequard syndrome. N Engl J Med 1999;340:285

3. Weinstein JM, Zweifel TJ, Stanley T. Congenital Horner's syndrome. Arch Ophthalmol 1980;98:1074-8.

4. Asch AJ. Turner's syndrome occurring with Horner's syndrome. Am J Dis Child 1979;133:827-30.

5. Baudet E, al-Qudah A. Late results of the subclavian flap repair of coarctation in infancy. J Cardiovasc Surg 1989;30:445-9.

6. van Heurn LW, Wong CM, Spiegelhalter DJ, Sorensen K, de Leval MR, Stark J, et al. Surgical treatment of aortic coarctation in infants younger than three months: 1985 to 1990. Success of extended end-to-end arch aortoplasty. J Thorac Cardiovasc Surg 1994;107:74-85. 